\section{Proteine, induziert durch Vitamin-K-Mangel}

T. Stief und P. Kiefer

Institut für Laboratoriumsmedizin und Pathobiochemie, Krankenhaus der Philipps-Universität, Marburg, Deutschland

Synonym(e) PIVKA; Acarboxyproteine

Englischer Begriff proteins induced by vitamin $\mathrm{K}$ absence (PIVKA)

Definition Bei Vitamin-K-Mangel oder unter Cumarintherapie werden von der Leber auch gerinnungsinaktive Vorstufen (PIVKA) der Faktoren II, VII, IX, X, PC, PS (F2, F2, F9, F10 = Prothrombinkomplex = PPSB), denen die $\gamma$-Carboxylierung ihrer N-terminalen Glutaminsäurereste fehlen, ins Blut abgegeben.

Beschreibung Die Vitamin-K-abhängigen Gerinnungsfaktoren ( $\triangleright$ Protein $\mathrm{C}$, $\triangleright$ Protein S, F2, F7, F9, F10) werden in der Leber synthetisiert und Vitamin-K-abhängig posttranslational modifiziert: diese Modifizierung N-ständiger Glutaminsäurereste durch $\gamma$-Carboxylierung zu Carboxy-Glutaminsäureresten (Gla) ist erforderlich, damit Calcium-Ionen an die Gerinnungsfaktoren binden, um dann mit Phospholipidoberflächen zu interagieren. In Abwesenheit von Vitamin $\mathrm{K}$ werden von der Leber die nicht modifizierten, gerinnungsinaktiven Vorstufen (PIVKA) in das Blut abgegeben. Die $\gamma$-Carboxylierung der Gerinnungsfaktoren wird von einer Carboxylase katalysiert, die Vitamin $\mathrm{K}$ in reduzierter Form
(Vitamin $\mathrm{KH}_{2}$ ), molekularen Sauerstoff und Kohlendioxid benötigt. Im Verlauf der Reaktion wird $\mathrm{VKH}_{2}$ zu VK-Epoxid oxidiert. VK-Epoxid wird durch die VK-Epoxidreduktase zu VK recycled, das wiederum durch die VK-Reduktase zu $\mathrm{VKH}_{2}$ reduziert wird. Beide Reduktasen (Vitamin-K-Reduktase und Vitamin-K-Epoxid-Reduktase) können durch Cumarine inhibiert werden. Dieser Vitamin-K-Zyklus ist nachfolgend dargestellt.

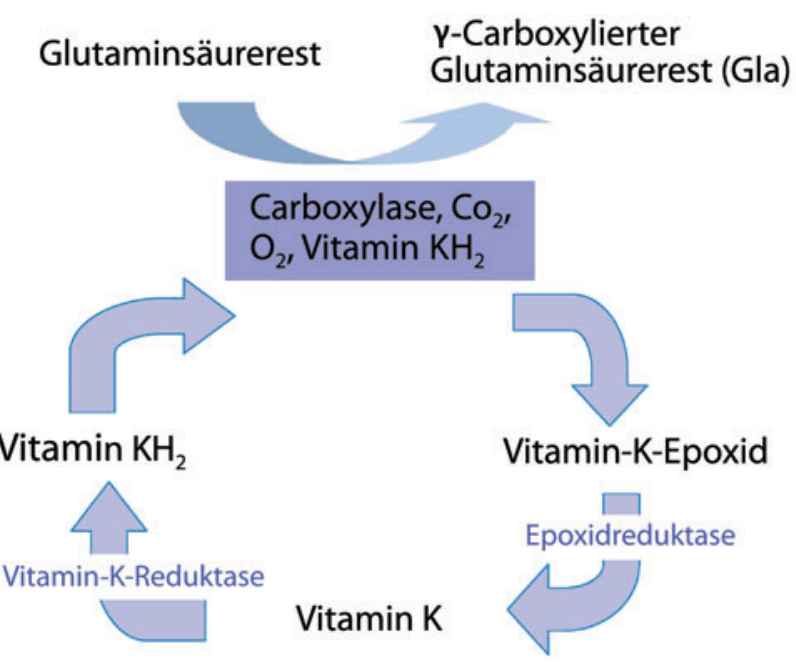

\section{Literatur}

Hirsh J, Dalen J, Anderson DR et al (2001) Oral anticoagulants: mechanism of action, clinical effectiveness, and optimal therapeutic range. Chest 119:8S-21S 